\title{
Effects of Body Fat Distribution on Regional Lipolysis in Obesity
}

Mary L. Martin and Michael D. Jensen

Endocrine Research Unit, Department of Internal Medicine, Mayo Clinic, Rochester, Minnesota 55905

\begin{abstract}
To determine the contribution of the major body fat depots to systemic free fatty acid (FFA) availability, palmitate $\left(\left[1-{ }^{14} \mathrm{C}\right]-\right.$ palmitate) release was measured from leg (lower body) and non-leg (upper body) fat in eight upper body obese (UB Ob), six lower body obese (LB Ob), and six nonobese (Non Ob) agematched premenopausal women in the overnight postabsorptive state. Splanchnic palmitate release was determined in 16 of these subjects. Results: total palmitate release was greater in UB Ob $(P<0.005)$ than LB Ob or Non Ob women $(161 \pm 16$ vs. $111 \pm 9 \mathrm{vs} .92 \pm 9 \mu \mathrm{mol} / \mathrm{min}$, respectively). Despite increased leg fat mass in obese women, leg palmitate release was similar in each group. Therefore, leg fat palmitate release was greater in Non Ob women than LB Ob $(P<0.01)$ or UB Ob $(P=0.06)$ women $\left(3.7 \pm 0.3 \mathrm{vs} .2 .4 \pm 0.2 \mathrm{vs} .2 .7 \pm 0.2 \mu \mathrm{mol} \cdot \mathrm{kg} \mathrm{fat}^{-1} \cdot \mathrm{min}^{-1}\right.$, respectively). Upper body fat palmitate release was less ( $P$ $<0.01)$ in $\mathrm{LB}$ Ob than Non Ob or UB Ob women (3.0 $\pm 0.4 \mathrm{vs}$. $5.0 \pm 0.3$ vs. $4.9 \pm 0.4 \mu \mathrm{mol} \cdot \mathrm{kg} \mathrm{fat}{ }^{-1} \cdot \mathrm{min}^{-1}$, respectively). Splanchnic palmitate release accounted for $20-32 \%$ of upper body fat palmitate release in each group $(P=$ NS between groups). Leg fat palmitate release was significantly less than upper body fat palmitate release. We conclude that the major difference in resting FFA metabolism between $\mathrm{UB} O \mathrm{Ob}$ and $\mathrm{LB}$ $\mathrm{Ob}$ women is the ability of the later to down-regulate upper body fat lipolysis to maintain normal FFA availability. (J. Clin. Invest. 1991. 88:609-613.) Key words: free fatty acid • body composition $\cdot\left[1-{ }^{14}\right.$ C $]$ palmitate
\end{abstract}

\section{Introduction}

Upper body obesity, as assessed by waist-hip circumference ratio (WHR), ${ }^{1}$ is a major risk factor for hypertension, glucose intolerance, and hypertriglyceridemia (1-3). Conversely, individuals with lower body obesity may have comparable amounts of body fat but remain relatively free of the metabolic consequences of obesity. Although the mechanism(s) by which upper body obesity results in adverse health effects is unknown, it has been suggested that increased free fatty acid (FFA) availability, resulting from increased effective adipose tissue lipolysis, might be directly responsible for some of the observed abnormalities (4-6).

Address reprint requests to Dr. Jensen, Endocrine Research Unit, 5-164 West Joseph, Rochester, MN 55905.

Received for publication 11 December 1990 and in revised form 26 March 1991.

1. Abbreviations used in this paper: BMI, body mass index; LBM, lean body mass; WHR, waist-hip ratio.

J. Clin. Invest.

(c) The American Society for Clinical Investigation, Inc.

0021-9738/91/08/0609/05 \$2.00

Volume 88, August 1991, 609-613
We have previously reported that upper body obesity in women is associated with increased FFA availability relative to lean tissue needs compared with nonobese and lower body obese women (7). In order for lower body obese women to maintain appropriate FFA availability despite increased fat mass, there must be down-regulation of lipolysis to prevent FFA release from increasing in proportion to body fat. Conversely, this process must fail to some extent in upper body obese women. Whether this failure is a regional, versus generalized, phenomena is unknown. The former hypothesis is supported by the finding of adipose tissue lipolytic heterogeneity in vitro $(8,9)$ and in vivo $(10,11)$.

Unfortunately, there is no information regarding the potential contributions of the major body fat depots to systemic FFA availability in vivo in humans. To address these issues we have measured FFA release from leg, non-leg, and splanchnic beds in nonobese women and obese women with differing body fat distributions. Our findings localize upper body subcutaneous fat as a major site of excess FFA release in healthy, premenopausal upper body obese women.

\section{Methods}

Subjects. Informed written consent was obtained from 14 healthy, moderately obese (body mass index [BMI] $29-36 \mathrm{~kg} / \mathrm{m}^{2}$ ) premenopausal women and six nonobese (BMI $20-24 \mathrm{~kg} / \mathrm{m}^{2}$ ) premenopausal women. Obese subjects were selected such that six were defined as lower body obese (WHR < 0.76) and eight subjects were selected as upper body obese (WHR > 0.85). Waist circumferences were measured at the natural (smallest) waist with the subject in the supine position, and hip measurements were made at the maximum circumference with the subject standing with feet together. All women were in good health and taking no medications known to affect FFA metabolism. The volunteers had maintained a stable weight for $>2$ mo before the studies and were instructed to consume a minimum of $200 \mathrm{~g}$ of carbohydrate daily for at least 2 wk before the studies. A summary of the subjects' clinical characteristics is provided in Table I. Because of the demographics of our region, all of the women were Caucasian.

Materials. $\left[1-{ }^{14} \mathrm{C}\right]$ palmitate (Research Products International Corp., Mount Prospect, IL) was prepared for intravenous infusion as previously described (12). Indocyanine green (Cardio-Green, Becton, Dickinson \& Co., Cockeysville, MD) was prepared as a $1.9 \%$ human serum albumin solution in $0.40 \%$ sodium chloride.

Assays. Plasma palmitate concentration and specific activity were determined using high-performance liquid chromatography (HPLC) $(13,14)$. Plasma insulin concentrations were measured by radioimmunoassay (15). Plasma indocyanine green concentrations were measured by a modification of a previously published HPLC technique (16). Briefly, $0.5 \mathrm{ml}$ of plasma was mixed with $50 \mu \mathrm{l}$ of methanolic diazepam $(1 \mathrm{mg}$ in $100 \mathrm{ml}$ ) as the internal standard, and $0.5 \mathrm{ml}$ of acetonitrile was added to precipitate plasma proteins. This solution was vortexed and centrifuged at $1,700 \mathrm{~g}$ for $1 \mathrm{~min}$. The supernatant was injected onto an HPLC column within 40 min of sample preparation. Chromatography was performed on a $\mathrm{C} 18$ reverse-phase $10-\mu \mathrm{m}$ column and eluted with $40 \%$ acetonitrile and $60 \% 0.05 \mathrm{M} \mathrm{Na}_{2} \mathrm{PO}_{4}$ buffer solution $(\mathrm{pH}=6.0)$ at $2 \mathrm{ml} / \mathrm{min}$. Wavelength detection was $214 \mathrm{nM}$. Subject samples were compared to a calibration curve which was constructed from identi- 


\begin{tabular}{|c|c|c|c|c|c|c|c|c|}
\hline & Age & Weight & BMI & WHR & LBM & $\begin{array}{c}\text { Serum } \\
\text { triglycerides }\end{array}$ & $\begin{array}{c}\text { Serum } \\
\text { cholesterol }\end{array}$ & $\begin{array}{l}\text { Plasma } \\
\text { insulin }\end{array}$ \\
\hline & $y r$ & $k g$ & $\mathrm{~kg} / \mathrm{m}^{2}$ & & $k g$ & mmol/liter & $\mathrm{mmol} / \mathrm{liter}$ & pmol/liter \\
\hline $\mathrm{UB} \mathrm{Ob}(n=8)$ & $42 \pm 1$ & $86.5 \pm 4.1^{*}$ & $32.7 \pm 0.9$ & $0.88 \pm 0.01^{*}$ & $42.8 \pm 1.0$ & $1.72 \pm 0.23$ & $5.65 \pm 0.26$ & $82 \pm 16$ \\
\hline $\mathrm{LB} \mathrm{Ob}(n=6)$ & $38 \pm 2$ & $86.6 \pm 3.5^{*}$ & $33.3 \pm 0.8$ & $0.74 \pm 0.02$ & $45.9 \pm 1.7$ & $1.08 \pm 0.26$ & $4.78 \pm 0.26$ & $57 \pm 12$ \\
\hline Non $\mathrm{Ob}(n=6)$ & $38 \pm 2$ & $63.7 \pm 2.7$ & $22.9 \pm 0.5$ & $0.71 \pm 0.01$ & $43.7 \pm 1.7$ & $0.72 \pm 0.10$ & $4.58 \pm 0.49$ & $51 \pm 5$ \\
\hline
\end{tabular}

Abbreviations: UB Ob, upper body obese; LB Ob, lower body obese; Non Ob, nonobese. Because waist to hip circumference ratios were not random variables between obese subjects, these values were not analyzed $\mathrm{UB} \mathrm{Ob}$ vs. $\mathrm{LB} \mathrm{Ob}$.

${ }^{*} P<0.001 \mathrm{cf}$. Non $\mathrm{Ob}$

cally treated standards. Analysis of plasma samples was performed immediately after each study since degradation of indocyanine green after overnight freezing was found to occur. Subjects having hepatic vein indocyanine green concentrations of $>0.5 \mathrm{mg} /$ liter were excluded from the splanchnic portion of the study because these samples were considered to have been contaminated with inferior vena caval blood.

Protocol. Lean body mass (LBM) was measured with tritiated water space and/or body potassium counting (17) before the study. Total body and regional fat content were measured using dual-energy $x$-ray absorptiometry (model DPX, Lunar Radiation Corp., Madison, WI) (18). Subjects were scanned using the 20 -min whole-body scan time, and region of interest analysis was performed using software version 3.1 (18). Calibration of the model DPX was confirmed every 1-2 wk with a series of four phantoms composed of a range (4-61\% fat) of known quantities of fat and lean (19) (kindly provided by the Research and Development Section, George A. Hormel Co., Austin, MN). Extensive in vitro and in vivo studies of our model DPX were performed before and during these experiments which confirmed the accuracy of the measurements (M. D. Jensen and H. W. Wahner, unpublished observations). Leg fat content was estimated by using the software program to isolate the leg that was undergoing the femoral artery/femoral vein catheterization studies. Total abdominal fat content (20) was estimated by using the region of interest program to quantitate the amount of fat between the pubic rami and the diaphragm. Abdominal skinfold thicknesses were measured in four separate areas of the abdomen using skinfold calipers.

Each subject was admitted to the Mayo Clinic General Clinical Research Center the evening before the study where they received a standard evening meal. The following morning, after an overnight fast, an 18-gauge infusion catheter was placed in a forearm vein, and patency was maintained with a $0.45 \% \mathrm{NaCl}$ infusion at $20 \mathrm{ml} / \mathrm{h}$. Blood was sampled before starting the isotope and indocyanine green infusions to be used for background palmitate specific activity and for construction of the indocyanine green calibration curve.

The volunteers were transferred to the Cardiac Catheterization Laboratory where the $\left[1-{ }^{14} \mathrm{C}\right]$ palmitate $(\sim 0.5 \mu \mathrm{Ci} / \mathrm{min})$ and indocyanine green (12-mg priming dose, $1.1 \mathrm{mg} / \mathrm{min}$ ) infusions were started at least $20 \mathrm{~min}$ before blood sampling. A 6 French teflon sheath was inserted using standard percutaneous technique into the right femoral artery. Through the sheath a 5 French pigtail was inserted and positioned in the iliac artery $10 \mathrm{~cm}$ distal to the bifurcation of the aorta; this was used for arterial blood sampling. After placement of the arterial catheters the indocyanine green infusion was transferred to the femoral artery sheath and allowed to infuse for a minimum of $5 \mathrm{~min}$ before blood sampling.

An 8 French teflon sheath with a 7 French no. 2 cobra catheter was then introduced into the right femoral vein. The cobra catheter was placed under fluoroscopic guidance into the wedge position of the hepatic vein. $5 \mathrm{ml}$ of contrast dye was injected to confirm placement. The blood sampling tip of the femoral vein catheter sheath was placed approximately at the level of the inguinal ligament. Nonheparinized $0.45 \% \mathrm{NaCl}$ was infused through each catheter to maintain patency.
Five sets of blood samples were obtained at 4-min intervals from the hepatic vein, femoral vein, and femoral artery sites. After completion of blood samples all catheters were removed and local hemostasis was obtained. The subjects remained in the hospital for the following $24 \mathrm{~h}$ under observation.

Calculations. Plasma palmitate concentration and specific activity were constant over the sampling intervals; therefore, steady-state equations were used to calculate palmitate flux (12) using the mean palmitate specific activity for each subject. Hepatic plasma flow was calculated using the Fick principle and plasma indocyanine green clearance as previously described (21). Leg plasma flow was calculated according to the method of Jordfelt and Wahren (22). Regional (splanchnic and leg) palmitate uptake and release were calculated using previously published equations (11).

The following values were calculated using the palmitate kinetic data combined with body composition analysis:

Palmitate release per kilogram of LBM

$=$ total palmitate flux $\div$ kilogram total of LBM.

Leg fat palmitate release

$=$ leg palmitate release (micromoles per minute)

$\div$ leg fat (kilograms).

Upper body fat palmitate release

$=($ total palmitate flux $-[$ leg palmitate release $\times 2])$

$\div($ total body fat $-[$ leg fat $\times 2])=$ upper body palmitate release

$\div$ upper body fat.

To examine the potential contribution of visceral fat to total abdominal fat in these subjects we estimated subcutaneous and visceral fat mass as follows: (a) abdominal circumference was used to calculate abdominal radius, $(b)$ abdominal radius - mean subcutaneous skinfold thickness $=$ radius of intra-abdominal tissues; $(c)$ total abdominal area - intra-abdominal area $=$ subcutaneous adipose tissue area; $(d)$ Subcutaneous adipose tissue area $\times$ abdominal length $=$ subcutaneous adipose tissue volume; (e) Subcutaneous adipose tissue volume $\times 0.83$ (the percentage of fat in adipose tissue) $(23) \times 0.9$ (density of fat in grams per cubic centimeter) $=$ abdominal subcutaneous fat (grams); and ( $f$ ) total abdominal fat (kilograms) - abdominal subcutaneous fat (kilograms) $=$ visceral fat.

Statistics. All results are expressed as mean \pm standard error of the mean. Comparisons among groups were made using analysis of variance and subsequent nonpaired $t$ test. Comparisons between upper body and leg palmitate release were made using a two-tailed paired Student's $t$ test. 
Table II. Body Fat Content and Anthropomorphics

\begin{tabular}{lccccc}
\hline & Total body fat & Leg fat & Abdominal fat & $\begin{array}{c}\text { Waist } \\
\text { circumference }\end{array}$ & $\begin{array}{c}\text { Abdominal } \\
\text { skinfold thickness }\end{array}$ \\
\hline & $k g$ & $k g$ & $k g$ & $c m$ & $c m$ \\
UB Ob $(n=8)$ & $38.7 \pm 3.0$ & $7.2 \pm 0.6$ & $13.6 \pm 1.0$ & $99 \pm 3^{*}$ & $3.8 \pm 0.3$ \\
LB Ob $(n=6)$ & $40.1 \pm 3.5$ & $8.6 \pm 0.9$ & $11.8 \pm 0.8$ & $87 \pm 2^{*}$ & $3.3 \pm 0.1$ \\
Non Ob $(n=6)$ & $20.6 \pm 1.5^{*}$ & $4.5 \pm 0.5^{*}$ & $4.8 \pm 0.3^{*}$ & $71 \pm 2^{*}$ & $1.6 \pm 0.2^{*}$ \\
\hline
\end{tabular}

Abbreviations as in Table I. Leg fat content refers to the leg from which palmitate kinetic data were obtained.

$* P<0.001 \mathrm{cf}$. other groups.

\section{Results}

Subject characteristics (Table I). The mean ages and amount of LBM were not different in the three groups of women. Women with upper body and lower body obesity did not differ with respect to their degree of overweight, total weight, or percent body fat. Serum triglyceride, cholesterol, and fasting plasma insulin concentrations were modestly, but not significantly, increased in upper body obese women compared to lower body obese or nonobese women. WHR were intentionally selected to be different in upper body obese and lower body obese women, and there was no significant difference between WHR of lower body obese and nonobese women. Upper body obese women tended to have higher $(P<0.05)$ fasting plasma glucose concentrations than lower body obese or nonobese women ( $5.8 \pm 0.2$ vs. $5.0 \pm 0.1$ vs. $5.0 \pm 0.1 \mathrm{mmol} /$ liter, respectively). Likewise, systolic ( $125 \pm 8$ vs. $117 \pm 7$ vs. $107 \pm 4 \mathrm{mmHg}$, respectively) and diastolic ( $81 \pm 5$ vs. $78 \pm 3$ vs. $75 \pm 6 \mathrm{mmHg}$, respectively) blood pressures were slightly, but not significantly greater in upper body obese than lower body obese and nonobese women.

Body fat content (Table II). Total body fat mass was similar in both groups of obese women and greater $(P<0.001)$ than that present in nonobese women. As expected, abdominal fat content was greater in upper body obese than lower body obese women, whereas leg fat mass was greater in lower body obese than upper body obese women. Although these differences were not statistically significant, the contribution of leg fat to total body fat in lower body obese and nonobese women $(41 \pm 1 \%$ vs. $43 \pm 2 \%$, respectively, $P=\mathrm{NS})$ was greater $(P$ $<0.05)$ than in upper body obese women $(36 \pm 1 \%)$.

Using the calculations outlined in the Methods section, abdominal subcutaneous fat was estimated to be $9.7 \pm 0.9$, $7.4 \pm 0.4$, and $3.1 \pm 0.5 \mathrm{~kg}$ in upper body obese, lower body obese, and nonobese women, respectively (each value significantly different from each other value, $P<0.05$ ). Thus, visceral fat was calculated to be $3.9 \pm 0.6,4.4 \pm 1.0$, and $1.8 \pm 0.5 \mathrm{~kg}$ in upper body obese, lower body obese, and nonobese women. The value for nonobese women is less $(P<0.05)$ than both groups of obese women, whose values were not statistically different.

Palmitate kinetics (Table III, Figs. 1 and 2). Total palmitate flux and palmitate flux corrected for LBM was greater (both $P<0.005$ ) in upper body obese than lower body obese and nonobese women, despite no significant differences in plasma palmitate concentrations. Palmitate flux values were not significantly different in lower body obese and nonobese women.
Leg plasma flow was not different in upper body obese, lower body obese, and nonobese women $(240 \pm 27,239 \pm 20$, and $254 \pm 30 \mathrm{ml} / \mathrm{min}$ ). Despite the remarkable differences in leg fat content, leg palmitate uptake and release were similar in all three groups of women. Leg fat palmitate release in nonobese women $\left(3.7 \pm 0.3 \mu \mathrm{mol} \cdot \mathrm{kgfat}^{-1} \cdot \mathrm{min}^{-1}\right)$ was greater than lower body obese $\left(2.4 \pm 0.2 \mu \mathrm{mol} \cdot \mathrm{kgfat}^{-1} \cdot \mathrm{min}^{-1}, P<0.01\right)$ and upper body obese $\left(2.7 \pm 0.2 \mu \mathrm{mol} \cdot \mathrm{kgfat}^{-1} \cdot \mathrm{min}^{-1}, P=0.06\right)$ women (Fig. 1).

For all women, upper body fat palmitate release was greater than leg fat palmitate release $(4.3 \pm 0.3$ vs. $2.9 \pm 0.2 \mu \mathrm{mol} \cdot \mathrm{kg}$ $\left.\mathrm{fat}^{-1} \cdot \mathrm{min}^{-1}, n=20, P<0.005\right)$. Within groups, upper body fat palmitate release was also greater than leg fat palmitate release (upper body obese $4.9 \pm 0.4$ vs. $2.7 \pm 0.3, P<0.05$, lower body obese $3.0 \pm 0.4$ vs. $2.4 \pm 0.2, P=0.20$, and nonobese $5.0 \pm 0.3$ vs.

Table III. Palmitate Kinetics

\begin{tabular}{|c|c|c|c|}
\hline \multicolumn{4}{|c|}{ Systemic } \\
\hline & $\begin{array}{c}\text { Arterial } \\
\text { concentration }\end{array}$ & $\begin{array}{l}\text { Total } \\
\text { flux }\end{array}$ & Flux/LBM \\
\hline & 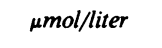 & $\mu \mathrm{mol} / \mathrm{min}$ & $\mu \mathrm{mol} \cdot \mathrm{kg} \mathrm{LBM}{ }^{-1} \cdot \mathrm{min}^{-1}$ \\
\hline UB Ob $(n=8)$ & $163 \pm 9$ & $161 \pm 16^{*}$ & $3.3 \pm 0.2^{*}$ \\
\hline $\mathrm{LB} \mathrm{Ob}(n=6)$ & $148 \pm 13$ & $111 \pm 9$ & $2.3 \pm 0.2$ \\
\hline Non Ob $(n=6)$ & $144 \pm 16$ & $92 \pm 9$ & $2.1 \pm 0.2$ \\
\hline \multicolumn{4}{|c|}{ Leg } \\
\hline & $\begin{array}{l}\text { Femoral vein } \\
\text { concentration }\end{array}$ & $\begin{array}{c}\text { Leg } \\
\text { uptake }\end{array}$ & $\begin{array}{c}\text { Leg } \\
\text { release }\end{array}$ \\
\hline & umol/liter & $\mu \mathrm{mol} / \mathrm{min}$ & $\mu \mathrm{mol} / \mathrm{min}$ \\
\hline $\mathrm{UB} \mathrm{Ob}(n=8)$ & $192 \pm 13$ & $12.8 \pm 1.6$ & $19.4 \pm 2.4$ \\
\hline $\mathrm{LB} \mathrm{Ob}(n=6)$ & $178 \pm 15$ & $12.0 \pm 0.8$ & $19.6 \pm 1.5$ \\
\hline Non Ob $(n=6)$ & $162 \pm 21$ & $12.0 \pm 1.3$ & $16.3 \pm 2.2$ \\
\hline \multicolumn{4}{|c|}{ Splanchnic } \\
\hline & $\begin{array}{l}\text { Hepatic vein } \\
\text { concentration }\end{array}$ & $\begin{array}{l}\text { Splanchnic } \\
\text { uptake }\end{array}$ & $\begin{array}{l}\text { Splanchnic } \\
\text { release }\end{array}$ \\
\hline & 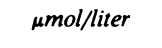 & $\mu \mathrm{mol} / \mathrm{min}$ & $\mu \mathrm{mol} / \mathrm{min}$ \\
\hline $\mathrm{UB} \mathrm{Ob}(n=7)$ & $116 \pm 10$ & $77.1 \pm 11.4$ & $24.3 \pm 5.1$ \\
\hline $\operatorname{LB~Ob}(n=4)$ & $100 \pm 15$ & $55.4 \pm 9.5$ & $16.4 \pm 3.8$ \\
\hline Non $\mathrm{Ob}(n=5)$ & $106 \pm 12$ & $48.2 \pm 9.3$ & $18.8 \pm 3.6$ \\
\hline
\end{tabular}

Abbreviations as in Table I.

${ }^{*} P<0.005$ cf. other groups. 


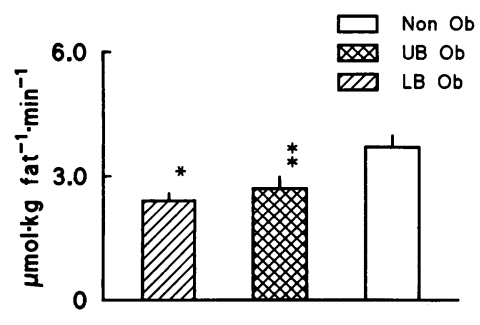

Figure 1. Palmitate release per kilogram of leg fat is shown for nonobese (Non $O b)$, upper body obese $(U B$ $O b$ ), and lower body obese $(L B O b)$ women. ${ }^{*} P<0.01$ cf. Non $\mathrm{Ob} ;{ }^{* *} P=0.06 \mathrm{cf}$. Non $\mathrm{Ob}$.

$\left.3.7 \pm 0.3 \mu \mathrm{mol} \cdot \mathrm{kg} \mathrm{fat}^{-1} \cdot \mathrm{min}^{-1}, P<0.01\right)$. Upper body fat palmitate release was less $(P<0.01)$ in lower body obese women than either nonobese or upper body obese women, whose values were not significantly different (Fig. 2).

Splanchnic plasma flow was $1,097 \pm 159,885 \pm 59$, and $991 \pm 118 \mathrm{ml} / \mathrm{min}$ in upper body obese, lower body obese, and nonobese women. None of the differences were statistically significant. Net splanchnic palmitate release was similar in all three groups of women and represented $20 \pm 5 \%, 23 \pm 6 \%$, and $32 \pm 5 \%$ of upper body palmitate release in upper body obese, lower body obese, and nonobese women, respectively $(P=$ NS between groups).

\section{Discussion}

These experiments were designed to examine whether lower body (leg) and upper body (non-leg) adipose tissue release FFA at different rates in humans and to determine whether the increased FFA flux present in upper body obesity is due to a regional, versus generalized, enhancement of lipolysis. By combining isotope dilution methodology for FFA turnover, limb and splanchnic balance techniques, together with regional and total body tissue composition analysis, we were able to determine that leg fat is less lipolytically active than upper body fat. In addition, we have confirmed our previous observation that upper body obesity is associated with increased FFA flux relative to lean tissue needs (7), and localized upper body subcutaneous fat as the site of excess FFA release in healthy, premenopausal upper body obese women.

It is now apparent that the heterogeneity of body fat distribution in obesity extends beyond the simple upper body vs. lower body model. Increased visceral fat is a better predictor of hypertension, hyperlipidemia, and non-insulin-dependent diabetes than upper body subcutaneous fat $(24,25)$. The selection of healthy, upper body obese women, taking no medications, might exclude viscerally obese women from these studies. Although our ability to exactly quantitate abdominal subcutaneous and visceral fat was somewhat limited by the methodology available to us at the time of these studies, the upper body obese volunteers would likely be characterized as

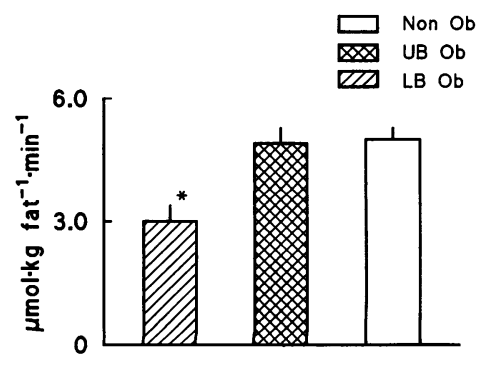

Figure 2. Palmitate release per kilogram upper body (non-leg) fat is shown for nonobese (Non $O b)$, upper body obese $(U B O b)$, and lower body obese ( $L B O b)$ women. ${ }^{*} P<0.01$. abdominal subcutaneous obesity. It is unknown whether visceral obesity would result in similar abnormalities of FFA metabolism.

Quantitation of our subjects' intra- and extra-abdominal fat with computed tomography (24-26) or magnetic resonance imaging (27) would have been preferable, however, the combination of dual-energy $x$-ray absorptiometry and anthropomorphic measurements provided data consistent with previous studies. Our estimates of abdominal subcutaneous area in nonobese women $\left(106 \pm 15 \mathrm{~cm}^{2}\right)$ is consistent with that reported by Baumgardner et al. (26) for midabdominal subcutaneous area measured by computed tomographic scanning. Mean, midabdominal visceral adipose tissue area (intra-abdominal plus retroperitoneal) in these same women (26) was $\sim 63 \mathrm{~cm}^{2}$, similar to what would be required to account for $1.8 \mathrm{~kg}$ of intra-abdominal fat in our nonobese women $\left(\sim 69 \mathrm{~cm}^{2}\right)$. Thus, we believe our estimates of abdominal subcutaneous and visceral fat in these subjects are likely close approximations of values which might have been obtained with more sophisticated methods. Studies are underway in our laboratory to test this supposition.

It is important to note that our measurement of splanchnic palmitate release is not a measure of splanchnic lipolysis. Note that splanchnic palmitate uptake was approximately threefold greater than release. Free fatty acid uptake occurs in both intestine and liver (28), whereas release of FFA into the portal circulation occurs from omental and mesenteric adipose tissue. Because the proportion of nonhepatic splanchnic FFA uptake in humans is unknown, splanchnic lipolysis cannot be predicted accurately. If all FFA uptake occurred in nonhepatic tissues, splanchnic FFA release would equal splanchnic lipolysis (a minimum estimate). If all splanchnic FFA uptake occurred in the liver, then the fractional uptake of FFA newly released into the portal circulation should equal fractional uptake of systemically delivered FFA $(\sim 50 \%)$. The maximum estimate of splanchnic lipolysis from these studies would then be approximately double splanchnic release $(\sim 30-50 \mu \mathrm{mol} / \mathrm{min})$. Visceral adipose tissue palmitate release might range from 4 to 22 $\mu \mathrm{mol} \cdot \mathrm{kg} \mathrm{fat}^{-1} \cdot \mathrm{min}^{-1}$. It does not appear to be possible to estimate more accurately visceral adipose tissue lipolysis in humans at the present time without access to the portal vein.

The most significant observation of the present studies is the difference in upper body fat lipolytic activity between lower body and upper body obese women. This difference is emphasized by the similarity of leg fat FFA release in these two groups of obese women. Despite increased upper body fat mass in lower body obese women, upper body FFA release was not elevated, thus preventing excess availability relative to lean tissue needs. It appears that as upper body fat mass increases in subcutaneous upper body obesity there is a failure to decrease lipolysis (e.g., FFA release per kilogram of fat remains identical to nonobese women). Thus, FFA flux in subcutaneous upper body obesity may increase in proportion to the increase in upper body, but not leg, fat. Despite the increased leg fat mass in both lower body obese and upper body obese women, leg palmitate release did not increase. This suggests that leg adipose tissue in these two types of obesity is down regulated with regard to lipolysis.

How upper body fat is down regulated in lower body obese women, and why this fails to occur in subcutaneous upper body obesity is unknown. Kissebah and colleagues (29) have demonstrated that abdominal subcutaneous adipocyte size is 
dramatically increased in upper body obese women compared with lower body obese and nonobese women, whereas thigh adipocyte size remains similar. Perhaps the increased size of upper body subcutaneous adipocytes in upper body obesity, with the resulting increase in unstimulated lipolysis (29), is permissive in the disregulation of upper body fat lipolysis. An understanding of the mechanism by which lower body obese women increase upper body fat mass by increasing fat cell number, whereas upper body obese women increase upper body fat cell size, might guide investigations into potential etiologic differences in these two types of obesity.

In addition to the potential effects of excess FFA to result in hypertriglyceridemia (6) and insulin resistance with regards to glucose utilization $(4,5)$, it has recently been demonstrated that FFA may affect hepatic insulin metabolism $(30,31)$. The exposure of hepatocytes to physiologic increases in FFA concentration reduced insulin clearance $(30,31)$. It is interesting to note that reduced hepatic insulin clearance has been found in upper body obese women (32).

In summary, the present in vivo studies are the first to show quantitative differences in FFA release from upper body versus lower body fat in overnight postabsorptive humans. In addition, we found that as leg fat mass increases in upper body and lower body obesity, no increase in leg FFA release occurs. In contrast, upper body FFA release increases proportionately with increased fat mass in subcutaneous upper body obesity, but not in lower body obese women. These observations not only localize the increased FFA released to upper body subcutaneous fat in upper body obesity, but suggest that a quantitation of fat in different body regions may lack predictive value for some of the metabolic consequences of obesity.

\section{Acknowledgments}

We gratefully acknowledge the expertise of David R. Holmes, Jr., M.D., Director of the Mayo Cardiac Catheterization Laboratory, as well as technical assistance of Mai Persson, the Mayo Clinic General Clinical Research Center and Cardiac Catheterization Laboratory staff, and the editorial skills of $J$. Ashenmacher.

This study was supported by grants DK-40484 and RR-0585 from the U. S. Public Health Service and by the Mayo Foundation.

\section{References}

1. Krotkiewski, M., P. Björntorp, L. Sjöström, and U. Smith. 1983. Impact of obesity on metabolism in men and women. J. Clin. Invest. 72:1150-1162.

2. Evans, D. J., R. G. Hoffmann, R. K. Kalkhoff, and A. H. Kissebah. 1984 Relationship of body fat topography to insulin sensitivity and metabolic profiles in premenopausal women. Metab. Clin. Exp. 33:68-75.

3. Evans, D. J., R. Murray, and A. H. Kissebah. 1984. Relationship between skeletal muscle insulin resistance, insulin-mediated glucose disposal, and insulin binding. J. Clin. Invest. 74:1515-1525.

4. Randle, P. J., P. B. Garland, C. N. Hales, and E. A. Newsholme. 1963. The glucose-fatty acid cycle; its role in insulin sensitivity and the metabolic disturbances of diabetes mellitus. Lancet. $i: 785-789$.

5. Ferrannini, E., E. J. Barrett, S. Bevilacqva, and R. A. DeFronzo. 1983. Effect of fatty acids on glucose production and utilization in man. J. Clin. Invest. 72:1737-1747.

6. Kissebah, A. H., S. Alfarsi, P. W. Adams, and V. Wynn. 1976. Role of insulin resistance in adipose tissue and liver in the pathogenesis of endogenous hypertriglyceridemia in man. Diabetologia. 12:563-571.
7. Jensen, M. D., M. W. Haymond, R. A. Rizza, P. E. Cryer, and J. M. Miles. 1989. Influence of body fat distribution on free fatty acid metabolism in obesity. J. Clin. Invest. 83:1168-1173.

8. Lafontan, M., L. Dang-Tran, and M. Berlan. 1979. Alpha-adrenergic antilipolytic effect of adrenaline in human fat cells of the thigh: comparison with adrenaline responsiveness of different fat deposits. Eur. J. Clin. Invest. 9:261266.

9. Wahrenberg, H., F. Lönnqvist, and P. Arner. 1989. Mechanisms underlying regional differences in lipolysis in human adipose tissue. J. Clin. Invest. 84:458-467.

10. Arner, P., E. Kriegholm, P. Engfeldt, and J. Bolinder. 1990. Adrenergic regulation of lipolysis in situ at rest and during exercise. J. Clin. Invest. 85:893898.

11. Jensen, M. D. 1991. Regulation of forearm lipolysis in different types of obesity: in vivo evidence for adipocyte heterogeneity. J. Clin. Invest. 87:187-193.

12. Jensen, M. D., M. W. Haymond, J. E. Gerich, P. E. Cryer, and J. M. Miles. 1987. Lipolysis during fasting: decreased suppression by insulin and increased stimulation by epinephrine. J. Clin. Invest. 87:207-213.

13. Miles, J. M., M. G. Ellman, K. L. McClean, and M. D. Jensen. 1987. Validation of a new method for determination of free fatty acid turnover. Am. J. Physiol. 252:E431-E438.

14. Jensen, M. D., P. J. Rogers, M. G. Ellman, and J. M. Miles. 1988. Choice of infusion-sampling mode for tracer studies of free fatty acid metabolism. Am. J. Physiol. 254 (Endocrinol. Metab. 17):E562-E565.

15. Herbert, V., K. S. Lav, G. W. Gottlieb, and S. J. Bleicher. 1965. Coatedcharcoal immunoassay of insulin. J. Clin. Endocrinol. Metab. 25:1375-1384.

16. Rappaport, P. L., and J. J. Thiessen. 1982. High-pressure liquid chromatographic analysis of indocyanine green. J. Pharm. Sci. 71:157-161.

17. Jensen, M. D., J. S. Braun, R. J. Vetter, and H. M. Marsh. 1988. Measurement of body potassium with a whole-body counter: relationship between lean body mass and resting energy expenditure. Mayo Clin. Proc. 63:864-868.

18. Mazess, R. B., H. S. Barden, J. P. Bisek, and J. Hanson. 1990. Dual-energy $\mathrm{x}$-ray absorptiometry for total-body and regional bone-mineral and soft-tissue composition. Am. J. Clin. Nutr. 51:1106-1112.

19. Wang, J., S. B. Heymsfield, M. Aulet, J. C. Thornton, and R. N. Pierson, Jr. 1989. Body fat from body density: underwater weighing vs. dual photon absorptiometry. Am. J. Physiol. 256 (Endocrinol. Metab. 19):E829-E834.

20. Schlemmer, A., C. Hassager, J. Haarbo, and C. Christiansen. 1990. Direct measurement of abdominal fat by dual photon absorptiometry. Int. J. Obes. 14:603-611.

21. Bradley, S. E., F. J. Ingelfinger, G. P. Bradley, and J. J. Curry. 1945. The estimation of hepatic blood flow in man. J. Clin. Invest. 24:890-897.

22. Jorfeldt, L., and J. Wahren. 1971. Leg blood flow during exercise in man. Clin. Sci. (Lond.). 41:459-473.

23. Garrow, J. S. 1982 . New approaches to body composition. Am. J. Clin. Nutr. 35:1152-1157.

24. Fujioka, S., Y. Matsuzawa, K. Tokunaga, and S. Tarui. 1987. Contribution of intra-abdominal fat accumulation to the impairment of glucose and lipid metabolism in human obesity. Metab. Clin. Exp. 36:54-59.

25. Després, J.-P., A. Nadeau, A. Tremblay, M. Ferland, S. Moorjani, P. J. Lupien, G. Theriault, S. Pinault, and C. Bouchard. 1989. Role of deep abdominal fat in the association between regional adipose tissue distribution and glucose tolerance in obese women. Diabetes. 38:304-309.

26. Baumgartner, R. N., S. B. Heymsfield, A. F. Roche, and M. Bernardino. 1988. Abdominal composition quantified by computed tomography. Am. J. Clin. Nutr. 48:936-945.

27. Seidell, J. C., G. J. G. Bakker, and K. van der Kooy. 1990. Imaging techniques for measuring adipose-tissue distribution: a comparison between computed tomography and 1.5-T magnetic resonance. Am. J. Clin. Nutr. 51:953957.

28. Basso, L. V., and R. J. Havel. 1970. Hepatic metabolism of free fatty acids in normal and diabetic dogs. J. Clin. Invest. 49:537-547.

29. Kissebah, A. H., N. Vydelingum, R. Murray, D. J. Evans, A. J. Hartz R. K. Kalkhoff, and P. W. Adams. 1982. Relation of body fat distribution to metabolic complications of obesity. J. Clin. Endocrinol. Metab. 54:254-260.

30. Svedberg, J., P. Björntorp, U. Smith, and P. Lönnroth. 1990. Free fatty acid inhibition of insulin binding, degradation, and action in isolated rat hepatocytes. Diabetes. 39:570-574.

31. Hennes, M. M. I., E. Shrago, and A. H. Kissebah. 1990. Receptor and postreceptor effects of free fatty acids (FFA) on hepatocyte insulin dynamics. Int. J. Obes. 14:831-841.

32. Peiris, A. N., R. A. Mueller, G. A. Smith, M. F. Struve, and A. H. Kissebah. 1986. Splanchnic insulin metabolism in obesity. Influence of body fat distribution. J. Clin. Invest. 78:1648-1657. 